\title{
Safety Netting through the Prevention and Detection of Child Abuse in Low and Middle Income Countries: Lessons from Pakistan
}

\author{
Kanwal Nayani', Muhammad Akbar Baig ${ }^{2}$, Nick Brown ${ }^{3}$, Asad Mian ${ }^{4}$ \\ ${ }^{1}$ Aga Khan University Hospital, Karachi, Pakistan \\ 2Department of Emergency Medicine, Aga Khan University Hospital, Karachi, Pakistan \\ ${ }^{3}$ Department of Pediatrics, Salisbury District Hospital, Wiltshire, Unite Kingdom \\ ${ }^{4}$ Department of Emergency Medicine, Pediatrics and Child Health, Aga Khan University Hospital, Karachi, Pakistan
}

\section{Dear Editor,}

According to $\mathrm{WHO}, 6.3$ million children died before the age of 5 years in 2013. Five percent of these deaths were due to injury and violence (1). In 2012, it was estimated that around 30,000 childhood deaths were caused due to non-accidental injury (NAI) (2). Child abuse or maltreatment can be physical, emotional, and/or sexual. Even negligence or neglect on the part of the caregiver that may cause harm to the child's physical and mental wellbeing constitutes abuse. Child abuse is most commonly detected is predominantly physical, and there is a large amount of NAls from high income countries (HICs). In the United States, there is an annual average of 24.6 deaths and disability from child abuse per 100,000 children (3), and in 2013, 3.5 million children were found to have been abused (4). A study conducted in the United Kingdom in 2005 reported that 16\% of young adults have experienced maltreatment as a child (5). There is, however, very little published data available on child NAI and intentional violence as it pertains to low and middle income countries (LMICs), and a global review by Mulpuri found such wide incidences of NAI (0.47-2,000 per 100,000) that the differences could only be attributed to differences in detection (6). There is some data available from surveys on accidental trauma and resulting mortality in children in Pakistan $(7,8)$, but what is the situation actually regarding NAI? Injury, overall, is reported as the third leading cause of death in children in Pakistan, with an annual injury mortality rate of 37 per 100,000 children aged 1-4 years (8). One can assume that much of this is accidental, but because no adequate screening is available for child NAl, there is a high likelihood that abuse is being overlooked.

Therefore, the main purpose of the present paper was to search the available biomedical literature relevant to child NAI in Pakistan and from that to tease out the epidemiology of the problem, especially that pertaining to presentations in the emergency department (ED), as many of the injured children are seen there. We argue that there is a need for the rapid development and implementation of ED-based screening as part of the management of children, with sus- pected NAI being seen in the EDs of LMICs in general and Pakistan in particular. In tandem with further research in this crucial area, we also make the case for an advocacy-based approach to facilitate health systems-related policy formulation because child safety is at stake.

We searched PubMed and Google Scholar for the following keywords: "Non-Accidental Injury," "Non-Accidental Trauma," "Pediatric," "Child," "Emergency Room,, "Intentional Injury," "Pakistan," and "Lower and Middle Income Countries." We used the MeSH term "Child Abuse" in our search. As there are limited articles published on child abuse in Pakistan, we also searched recent newspapers for information on the topic.

As injury is a frequent emergency-related presenting complaint, the pediatric ED is a likely place where child NAI could be detected. According to the U.K.'s National Institute of Health and Care Excellence (NICE) guidelines, it is important for the healthcare provider to be attentive and watchful and to pick up on certain clues from the interaction with the patient and the family, regarding NAI. For example, bruising or ligature marks, especially in a child too young to be moving independently. Also, bites, lacerations, head injury, occult fractures, and retinal hemorrhages may point toward NAl; hence, patients presenting with these should be suspected to have undergone NAI. It may also be suspected if the child is withdrawn or is extremely distressed or agitated (9).

Knowledge of other risk factors for child NAI is important, and such factors may be identified in the history. If risk factors are identified, the child could be evaluated for NAl, as described below. These factors include low socioeconomic conditions, mental health issues in the parent or caregiver, and after a major financial crisis, including a natural disaster. Other risk factors include long-term illness in the child and the caregiver being from outside the family (10). Maguire et al. (11) reported that injuries in younger children (2.5-3.7 years) were more likely to be due to abuse as compared to accidental injuries. Another key risk factor is a previous history of abuse (12). Other known factors include having a teenage parent or a single parent, parents being drug abusers, coming from a crowded household, un-

Correspondence to: Muhammad Akbar Baig e-mail: dr_akbar2007@hotmail.com 
employment and poverty, or parents themselves being subjected to child abuse when they were children (13).

A methodical approach is needed in the ED when a suspected case of child NAl is encountered. There are evidence-based guidelines for the proper management of victims of child abuse from places in the U.S., such as Stanford University Hospital. According to these guidelines, the child should be hospitalized, regardless of the extent of injuries, in order to isolate them from the possible source of abuse. Subsequently, it is necessary to treat the injuries, obtain relevant samples for testing, and extract information from the child, if possible, and to diagnose the child based on a proper history, examination, and lab tests. Informing the Children's Protective Services is also important, so that they can intervene and ensure a safer environment for the child (14).

Pakistan's Federal Law prohibits child abuse of any kind, and according to the Charter of Child Rights Act 2009, the child may be separated from the parent in the case of severe abuse or neglect (15). However, there is little implementation of this law, because, unlike in the developed world, there is a lack of formalized programs for screening and managing for child NAI in EDs across Pakistan. There is a need to develop proper protocols and referral services for such cases, in order to ensure protection of the child involved. One hypothetical approach is shown in Figure 1. As per that figure, utilization of a proper referral service, like the Children's Protective Services mentioned above, or maybe even the involvement of the law enforcement agencies, should be necessary next steps when a child with suspected NAI is encountered in the ED. Although it is difficult in principle to isolate the child from potentially abusive parents in LMICs, as the mode of payment for healthcare is out-of-pocket, it might be the only recourse available to ensure the child's safety, and it is permissible under the Federal Law, as stated above. A proper policy regarding the management of these patients needs to be set up that can be followed by the EDs and pediatric departments of hospitals throughout the country, so that proper protection and management of the child can be ensured.

Several preventative programs have been successfully employed in the developed world that can potentially be applicable to LMICs. For example, in one program, parents of newborn children were counseled about the harmful effects of shaking children and were given alternatives to consider if the child was crying, rather than-

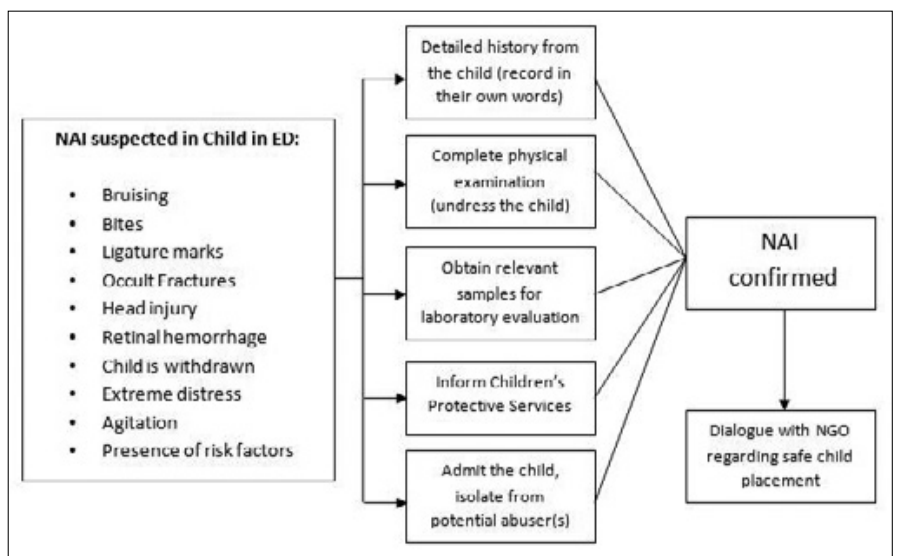

Figure 1. An approach to a child with suspected NAI presenting to the ED of an LMIC. This figure provides a hypothetical model for sCreening, identifying, and then managing a child suspected to have suffered NAI being encountered in the ED of an LMIC shaking or beating the child (16). Another prevention model was the Safe Environment for Every Kid (SEEK), in which pediatric residents recognized risk factors for child maltreatment in families and along with social workers, they intervened (17). Such interventions resulted in lower rates of child abuse in both these studies. The Nurse-Family Partnership model is also a good example of a community-based prevention program. In this model, trained nurses visit homes in the community regularly and educate them regarding the harmful effects of child abuse. The study also suggested that pediatricians regularly counsel parents in the clinic regarding child abuse (17).

Preventative programs mentioned above for developed countries might not be too cumbersome for implementation in Pakistan and other LMICs. For instance, pediatricians, pediatric residents and nurses, family physicians, and other healthcare providers involved in caring for children can be trained to identify risk factors for child NAI and to counsel the parents and caregivers accordingly. These counseling sessions regarding the dangers of child maltreatment could also be held during routine visits to the pediatric or family medicine clinics. Awareness sessions regarding child abuse may also be carried out in primary schools, where the children should be provided with various pathways to follow to report abuse, for example, by informing another adult or by calling a helpline like Madadgaar, a national telephone helpline that can be accessed by women and children to receive crisis management and legal advice for issues of abuse and intentional violence. According to this helpline, over 5000 cases of child abuse were reported across Pakistan over the span of ten months in 2012, and out of these, 1170 were injuries, according to a recent article in DAWN-a major English daily newspaper in Pakistan and one of the most credible sources of information (18). Admittedly, data from newspapers has its limitations as it is not held to the same rigor as that of biomedical publications. However, in a country like Pakistan where research studies on various aspects of child abuse might be hard to implement, epidemiological data that is available from any credible source should be utilized in order to tackle child NAI. It is important to note that data from national helplines might not give a true representation of the actual situation in Pakistan. There is always the possibility that the helpline has not been fully utilized and that many cases simply go unreported. Also, among the cases that are reported, we do not know if they end up receiving proper medical attention. Sahil is an NGO in Pakistan working for the welfare of children subjected to abuse. They organize such trainings and also offer counseling for these children, free of cost (19). An online forum named Laalteyn exists for victims of child abuse. Victims can anonymously post their stories and seek support from other victims (20).

Electronic and print media can be used to spread awareness regarding the issue, and a proper channel can be constructed to report such cases. Print media that is friendly, in the form of story books, can potentially sensitize children and their caregivers to child health-related issues. There is evidence that illustrations contribute a great deal to text coherence, and the presence of colorful pictures increases the child's interest in the text (21). We have attempted this for child literacy in general. We are in the process of piloting this for childhood trauma and injury, such as that from motor vehicle accidents, and its prevention. We are also developing something similar for NAI to engage children with colorful pictorial books to effectively communicate the perils of abuse prevalent in society as well as child NAI prevention information, albeit in a subtle way. Once the material is published and distributed in a local language such as Urdu for 
Pakistan and is found to be efficacious, then it can be translated into other languages, such as Hindi for India and Swahili for Africa; thus, the model can be replicated in other LMICs.

Through real advocacy, public and private health care-related partnerships, and national policy making, health systems can be reinforced, and through that, child NAl can holistically be tackled, thus ensuring a safer environment for children in Pakistan and other LMICs. By using similar approaches in the region and through international cooperation among ED-based trauma networks, this can potentially positively impact global child health.

\section{References}

1. Liu L, Oza S, Hogan D, Perin J, Rudan I, Lawn JE, et al. Global, regional, and national causes of child mortality in 2000-13, with projections to inform post-2015 priorities: an updated systematic analysis. Lancet 2015; 385: 430-40. [CrossRef]

2. WHO, Global Health Observatory Data Repository. [online] 2012 [cited 2015 December 15th]. Available from: URL: http://apps.who.int/gho/ data/node.main.12?lang=en

3. Phillips BC, Farst K, Aitken ME, Albert G. The current state of non-accidental head injury in Arkansas. J Ark Med Soc 2013; 109: 183-5.

4. Child Maltreatment. [online] 2013 [cited 2015 December 15th]. Available from: URL: http://www.acf.hhs.gov/programs/cb/resource/ child-maltreatment-2013

5. May-Chahal C, Cawson P. Measuring child maltreatment in the United Kingdom: a study of the prevalence of child abuse and neglect. Child Abuse Negl 2005; 29: 969-84. [CrossRef]

6. Mulpuri K, Slobogean BL, Tredwell SJ. The epidemiology of nonaccidental trauma in children. Clin Orthop Relat Res 2011;469: 759-67. [CrossRef]

7. Fatmi Z, Kazi A, Hadden WC, Bhutta ZA, Razzak JA, Pappas G. Incidence and pattern of unintentional injuries and resulting disability among children under 5 years of age: results of the National Health Survey of Pakistan. Paediatr Perinat Epidemiol 2009; 23: 229-38. [CrossRef]
8. Razzak JA, Khan UR, Zia N, Azam I. A child an hour: burden of injury deaths among children under 5 in Pakistan. Arch Dis Child 2013; 98: 867-71. [CrossRef]

9. Child maltreatment: when to suspect maltreatment in under $18 \mathrm{~s}, \mathrm{NICE}$ Guidelines [CG89] [online] 2009 [cited 2015 October 12th]. Available from: URL: https://www.nice.org.uk/guidance/cg89

10. Howe LD, Huttly SD, Abramsky T. Risk factors for injuries in young children in four developing countries: the Young Lives Study. Trop Med Int Health 2006; 11: 1557-66. [CrossRef]

11. Maguire SA, Upadhyaya M, Evans A, Mann MK, Haroon MM, Tempest V, et al. A systematic review of abusive visceral injuries in childhood--their range and recognition. Child Abuse Negl 2013; 37: 430-45. [CrossRef]

12. White $\mathrm{OG}$, Hindley N, Jones DP. Risk factors for child maltreatment recurrence: An updated systematic review. Med Sci Law 2015; 55: 259-77. [CrossRef]

13. Flaherty EG, Stirling J Jr. Clinical report-the pediatrician's role in child maltreatment prevention. Pediatrics 2010; 126: 833-41. [CrossRef]

14. Guidelines For Managing Child Abuse and Neglect Cases At Stanford University Hospital. [online] 2012 [cited 2015 November 15th]. Available from: URL: http://med.stanford.edu/gme/incoming_residents/documents/childAbuseReportingRequirements.pdf.

15. National laws on children's rights. [online] 2013 [cited 2015 December 1st]. Available from: URL: https://www.crin.org/en/library/publications/ pakistan-national-laws

16. Simonnet $\mathrm{H}$, Laurent-Vannier A, Yuan $\mathrm{W}$, Hully $\mathrm{M}$, Valimahomed $\mathrm{S}$, Bourennane $M$, et al. Parents' behavior in response to infant crying: abusive head trauma education. Child Abuse Negl 2014; 38: 1914-22. [CrossRef]

17. Feigelman S, Dubowitz H, Lane W, Grube L, Kim J. Training pediatric residents in a primary care clinic to help address psychosocial problems and prevent child maltreatment. Acad Pediatr 2011; 11:474-80. [CrossRef]

18. My stolen childhood. [online] 2014 [cited 2015 December 5th]. Available from: URL: http://www.dawn.com/news/1115058

19. Sahil - Har Bacha Mahfooz. [online] 2012 [cited 2015 December 10th]. Available from: URL: http://sahil.org/

20. Laalteyn - It is time we stopped hiding Child Abuse. [online] 2013 [cited 2015 December 15th]. Available from: URL: http://laalteyn.wordpress.com/

21. Fang Z. Illustrations, text, and the child reader: what are pictures in children's storybooks for? Reading Horizons 1996; 37: 130-42. 